\title{
Análise estrutural e geofísica em aquífero fraturado na região de Caçapava do Sul (RS)
}

Mariana Vieira Galvão de OLIVEIRA', César Augusto MOREIRA² Lívia Portes Innocente HELENE³ ${ }^{3}$ Antônio Elton da Silva LIMA $^{4}$. Instituto de Geociências e Ciências Exatas, Universidade Estadual Paulista - UNESP - Rio Claro - SP

Copyright 2018, SBGf - Sociedade Brasileira de Geofísica

Este texto foi preparado para a apresentação no VIII Simpósio Brasileiro de Geofísica. Salinópolis, 18 a 20 de setembro de 2018. Seu conteúdo foi revisado pelo Comitê Técnico do VIII SimBGf, mas não necessariamente representa a opinião da SBGf ou de seus associados. É proibida a reprodução total ou parcial deste material para propósitos comerciais sem prévia autorização da SBGf.

\section{Resumo}

A complexidade estrutural inerente em aquíferos fraturados, que condicionam o fluxo subterrâneo em zonas restritas, resulta numa elevada taxa de insucesso em perfurações de poços produtores. A análise de feições geomorfológicas e investigações indiretas prévias permitem a seleção de alvos favoráveis para captação subterrânea, uma alternativa racional em vilarejos distantes dos centros urbanos. Este trabalho aborda o uso combinado de levantamentos estruturais regionais/locais, seguido pela aplicação do método geofísico da Eletrorresistividade, a partir de linhas de tomografia elétrica, para seleção de pontos favoráveis a perfuração num aquífero fraturado em granito, com vistas ao abastecimento de um pequeno vilarejo distante $6 \mathrm{~km}$ a norte da cidade de Caçapava do Sul, extremo sul do Brasil. Foram realizadas 4 linhas de tomografia elétrica paralelas, numa área de interesse para captação de água subterrânea, seguido pela geração de modelos de inversão 2D e interpolação para análise em modelos pseudo 3D. O contato entre o solo superficial pouco espesso e o maciço granítico condiciona a existência de aquífero livre regional e a provável recarga do aquífero fraturado.

\section{Introdução}

A água é um recurso mineral de grande valor econômico e já foi motivo de diversas guerras em todo o mundo, pois as fontes de água doce e potável do planeta não estão distribuídas de forma homogênea pelo globo. O Brasil apesar de possuir a maior reserva de água doce do mundo enfrenta problemas relacionados a escassez de água em certas regiões de seu território. A coleta e distribuição de água para abastecimento da população brasileira é baseada na captação de fontes superficiais, representada principalmente por rios e lagos. Questões relacionadas à expansão dos centros urbanos em diferentes regiões do país, eventos sazonais de estiagem prolongada e o predomínio de infraestrutura precária em termos de saneamento básico, representam as principais causas de desabastecimento ou fornecimento intermitente de água aos centros urbanos. Uma alternativa viável para a falta água em certas localidades é o uso de sistemas isolados e independentes de captação. Em regiões desprovidas de fontes superficiais ou periféricas aos sistemas de distribuição convencionais, a coleta e abastecimento a partir de fontes subterrâneas pode ser uma alternativa de viabilidade técnica e econômica bastante interessante.
Existem inúmeros tipos de aquíferos sobre os mais diversos litotipos geológico, entretanto os aquíferos fraturados são particularmente desafiadores quanto à definição de áreas favoráveis a perfuração de poços de alta vazão devido a sua complexidade estrutural que condiciona o fluxo subterrâneo em zonas restritas. Sistemas de aquíferos fraturados são particularmente complexos, devido a condição de armazenamento e transmissão de água condicionado a planos de falha ou fratura. Uma alternativa técnica para seleção de locais favoráveis a captação subterrânea neste contexto, é a análise da morfologia e extração de feições lineares de relevo a partir de imagens de satélite, combinada com investigações indiretas por meio de métodos geofísicos (Hiscock, 2005; Brassington, 2007).

São mostrados resultados da correlação de dado estruturais e geoelétricos desenvolvidos numa porção do Granito Caçapava do Sul no município de Caçapava do Sul (RS). A região de estudo está localizada sobre parte da Suíte Granítica Caçapava do Sul pertencente ao Domínio Ocidental do Escudo Sul Rio Grandense. Tratase de um granitóide sintranscorrente intrudido no Complexo Metámorfico Vacacaí, assim possuindo uma foliação milonítica relacionada a eventos transcorrentes. A Suíte Granítica Caçapava do Sul compreende um corpo com formato aproximadamente dômico, com cerca de $25 \mathrm{Km}$ de extensão e orientado da direção N/S, datado de 549Ma e totalmente circundado por rochas metamórficas de baixo grau em contato abrupto (Nardi \& Bittencourt, 1989). O granito Caçapava na região de estudos apresenta revelo com declividade suave com variações de altitude entre $420 \mathrm{~m}$ e $350 \mathrm{~m}$. Contudo, seus limites com o Complexo Metamórfico Vacacaí apresentam declividade bastante acentuada, com variações bruscas de altitude.

O objetivo principal do estudo desenvolvido é conseguir estabelecer áreas para favoráveis a exploração de águas subterrâneas no Granito Caçapava do Sul através de correlação de dados estruturais e geoelétricos. Neste sentido, o presente trabalho apresenta e discute os resultados do uso combinado de análise geológica e estrutural regional, com levantamento geofísico por aplicação do método da Eletrorresistividade, no estudo de favorabilidade a captação de água subterrânea num vilarejo rural de um pequeno município do extremo Sul do Brasil, com escassez de fontes superficiais e sistema aquífero do tipo fraturado e contido em granitos. A aquisição de dados geoelétricos por meio de linhas de tomografia elétrica e posterior geração de modelos pseudo 3D a partir de inversão 2D, visa 0 reconhecimento de alinhamentos ou juntas estruturais em diversas profundidades, ou seja, alvos potencialmente 
interessantes para perfuração e captação de água subterrânea.

\section{Metodologia}

O estudo está localizado numa área rural no município de Caçapava do Sul (RS) (Figura 1), distante aproximadamente $12 \mathrm{~km}$ do centro da cidade em sentido noroeste, com relação a capital do Estado do Rio Grande do Sul, Porto Alegre está a 259 km.

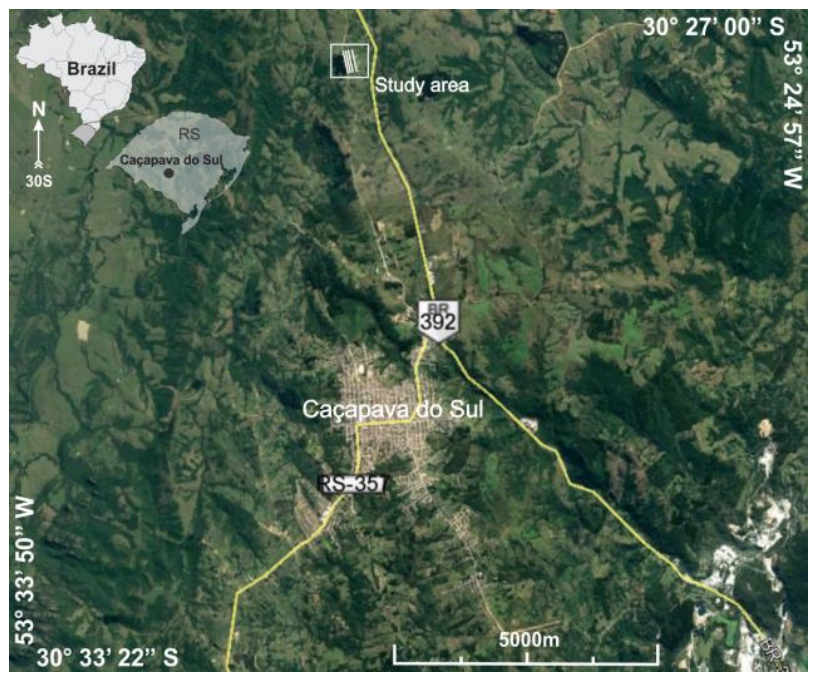

Figura 1: Localização da área de estudo.

Análise estrutural pré-campo foi realizada através do uso de imagens de satélite retiradas do Google Earth. Deste modo o fraturamento regional foi analisado a partir das feições lineares de relevo reconhecidas em imagens de satélite, é notado uma direção de lineações principal como NNW e em menor quantidade outras lineações NS e NNE. Essa análise estrutural básica preliminar das feições geomorfológicas somadas as investigações indiretas prévias, como a elaboração de uma roseta local com as atitudes das lineações presentes na área (Figura 2), permitiram a seleção inicial de alvos favoráveis para captação subterrânea.

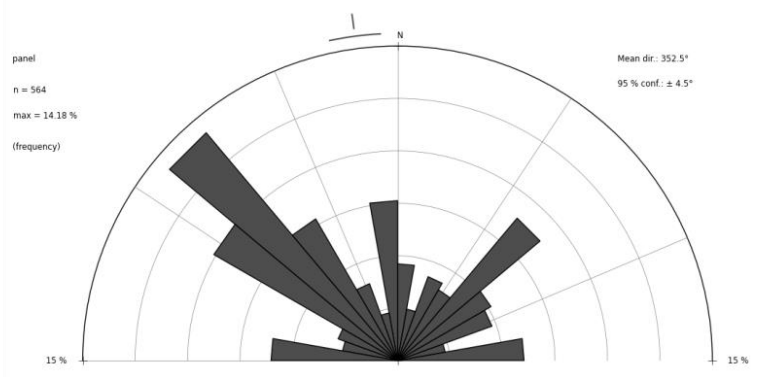

Figura 2: Roseta com as lineações retiradas de imagens de satélites.

O estudo de dados estruturais regionais, orientações obtidas em medidas de campo e a acessibilidade local foram fatores que definiram a quantidade e orientação das linhas de tomografia elétrica (Figura 3). A aquisição de dados geofísicos consistiu na realização de leituras de resistividade elétrica por aplicação da técnica de tomografia de resistividade elétrica (ERT) em arranjo Schlumberger, em 4 linhas de investigação paralelas entre si com comprimento individual de $420 \mathrm{~m}$ e espaçamento entre eletrodos de $10 \mathrm{~m}$, dispostas paralelamente e orientadas na direção $\mathrm{N} 282^{\circ}$.

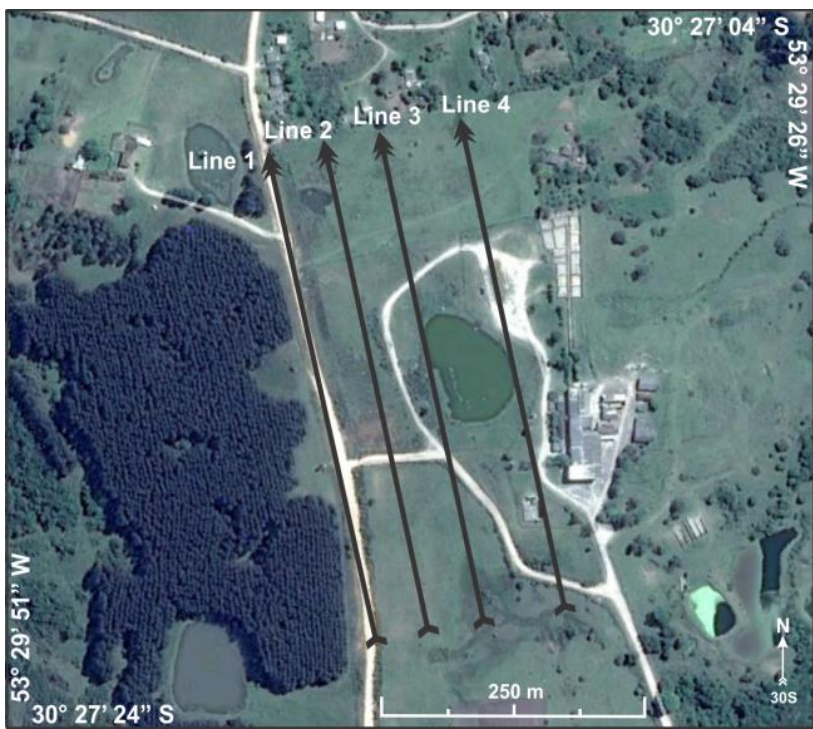

Figura 3: Foto área modificada com as linhas de aquisição de dados.

O equipamento geofísico utilizado foi o Resistivímetro ABEM Terrameter LS do Laboratório de Geofísica do Depto. de Geologia Aplicada - Unesp, devidamente configurado para efetuar as medidas de resistividade elétrica. Consiste em módulo único de transmissão e recepção de sinais automatizado a partir de programação prévia, com $250 \mathrm{~W}$, resolução de $1 \mu \mathrm{V}$ e corrente máxima de 2,5 A. Este equipamento permite a realização de ensaios de potencial espontâneo (SP), eletrorresistividade (ER) e polarização induzida (IP) por meio de ciclos periódicos de transmissão e recepção de sinais, cálculo automático da resistência de contato e do desvio padrão do conjunto de medidas.

Os dados obtidos em campo foram submetidos a uma modelagem 2D, por meio do software Res2Dinv, que gerou seções de resistividade em termos de distância $x$ profundidade, com escala gráfica logarítmica e intervalos de interpolação de valores em cores. A modelagem 2D permitiu a geração de modelos de inversão, cujo resultado analítico foi tabelado e modelado em termos interpolado em termos tridimensionais. Modelos geofísicos de visualização 3D derivados de seções 2D, também conhecidos com modelos quase-3D ou pseudo$3 \mathrm{D}$, proporcionam uma compreensão bastante ampla da complexidade de estruturas geológicas modelamento de litotipos ou depósitos minerais (Moreira et al., 2018).

\section{Resultados}

Os modelos de inversão de resistividade gerados a partir dos dados de tomografia elétrica são apresentados em escala única e logarítmica de valores para permitir a uma análise comparativa entre seções. Os valores de resistividade extremamente elevados são atribuídos a escala logarítmica e a faixa de variação de valores, entre $11.3 \Omega . m$ e $51851 \Omega . m$.

Os modelos de inversão são caracterizados por uma camada superficial com valores inferiores a $100 \Omega . m$ com 
ampla variação de espessura, mas limitados entre $0 \mathrm{~m}$ e $40 \mathrm{~m}$, que possivelmente reflete a interface de solo, saprolito e rocha alterada com fraturas, em contato basal com o embasamento granítico inalterado. Essa grande espessura ocorre devido à ação diferencial de processos de intemperismo no granito que estão associados a infiltração da água, sendo ela maior em áreas de maior fraturamento. Veios de quartzo também são áreas de maior resistência ao intemperismo assim como onde se encontra a rocha maciça.

$E$ existência de zonas restritas com valores inferiores a

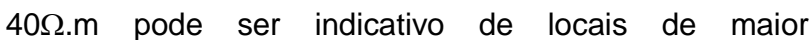
permeabilidade e acumulações no nível freático raso.

Os intervalos com valores superiores a $1000 \Omega . m$ representam o granito inalterado e são predominantes em todas as seções, embora a seção 3 apresente média de valores entre $1000 \Omega$.m e $5000 \Omega$.m, a menor faixa de variação dentre o conjunto das seções. As demais seções apresentam valores de resistividade predominantes entre $1000 \Omega . m$ e $20.000 \Omega . m$, com áreas limitadas com valores superiores a $50.000 \Omega$.m. Esta ampla variação de valores no intervalo de rocha inalterada pode ser relacionada feições estruturais que permitem ou restringem o acesso a água proveniente do aquífero livre, ou seja, são relacionadas a variações no teor de umidade.

Os valores de resistividade superiores a $20.000 \Omega$.m são atribuídos a escala logarítmica adotada durante o processamento dos dados, que objetivou tornar evidente o contraste de valores e o realce de feições lineares, possivelmente relacionadas a estruturas de fluxo em rocha inalterada, como falhas e fraturas (Figuras 4 E 5).

A orientação e inclinação das fraturas realçadas nas seções são condizentes com o padrão estrutural descrito durante a fase de reconhecimento geológico preliminar na região de estudos. Embora contidas em grande parte dentro de zonas altamente resistivas, exceto na seção 3, este conjunto de fraturas possivelmente apresenta conexão com os materiais superficiais de intemperismo e consequentemente com o aquífero livre.

Uma análise das posições das fraturas projetadas nas seções indica fraturas independentes e de pequena continuidade lateral, algo que a princípio revela um baixíssimo potencial aquífero no local. Mesmo no caso da seção 3 , com a menor média de valores de resistividade e consequentemente mais promissora a captação de água no sistema fraturado, a conectividade e continuidade lateral das estruturas é fundamental para recarga e fornecimento intermitente em captação por poços profundos.

Numa tentativa de possibilitar uma análise da continuidade lateral e eventual conectividade das fraturas reconhecidas nas seções $2 \mathrm{D}$, foram elaborados modelos de visualização 3D.

A análise dos modelos pseudo 3D revela o predomínio

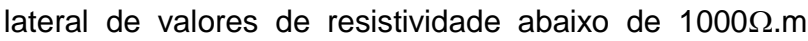
nos mapas cotas altimétricas de $395 \mathrm{~m}$ a $365 \mathrm{~m}$, conjunto ausente de evidências de feições lineares como fraturas ou falhas, possivelmente devido à natureza dos materiais constituintes. O mapa com cota altimetrias $395 \mathrm{~m}$ é caraterizado por amplas áreas difusas com resistividade elétrica abaixo de $100 \Omega$.m, evidência de acumulação de água aquífero livre em sistema poroso. Os mapas entre $385 \mathrm{~m}$ e $365 \mathrm{~m}$ apresentam redução das áreas de baixa resistividade e aumento das áreas onde predominam saprolito e rocha com graus variáveis de alteração. A partir da cota $355 \mathrm{~m}$ surgem indícios de feições lineares atribuídas a uma junta de fraturas orientadas em três

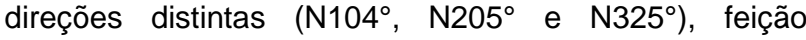
estrutural mais evidente nos mapas entre $345 \mathrm{~m}$ e $305 \mathrm{~m}$.

A análise conjunta entre modelos de inversão 2D e de visualização 3D (pseudo 3D) permitem algumas considerações. A padrão de resistividade abaixo de $4500 \Omega$.m predominante na seção 3, é essencialmente relacionado a orientação desta linha sobre a ao longo de uma fratura possivelmente saturada, que resultou num padrão relativamente homogêneo e distintos da média de valores da demais seções no horizonte granítico, ou seja, acima de $15000 \Omega$.m e abaixo da cota $355 \mathrm{~m}$.

Mesmo diante da ausência de evidências locais em superfície, um sistema de fraturas que controla o fluxo subterrâneo no interior de um maciço pode condicionar a rede de drenagem na superfície (Van Golf-Racht, 1982; Lee \& Farmer, 1993; Skinner \& Heinson, 2004; Singhal \& Gupta, 2010; Tassy et al., 2014; Ochoa-González et al., 2015; Zouhri \& Lutz, 2016).

Neste sentido, a análise regional de orientações de drenagens a partir do sistema de juntas descrito no modelamento geofísico 3D possibilitou o reconhecimento de sistemas estruturais análogos em superfície(Figura 6).

\section{Discussão e Conclusões}

Em aquíferos fraturados num maciço granítico a presença de fraturas e demais continuidades estruturais é de grande importância, pois são nesses locais que poderá se encontrar armazenamento e transmissão de água. Todavia essas descontinuidades necessitam ter conectividade lateral entre si e conexões com aquíferos livres, pois estas são condicionantes fundamentais para que possa ocorrer recarga do aquífero e assim talvez o tornando viável a exploração de seu recurso.

A técnica de tomografia elétrica é particularmente relevante no reconhecimento de descontinuidades estruturais lineares que podem servir potencialmente como caminhos de fluxo subterrâneo. Contudo, este trabalho revela um caso em que a estruturas verticalizadas reconhecidas em modelos de inversão 2D, relacionado a fraturas descritas em exposições rochosas, a princípio seriam pouco favoráveis em termos hidrogeológico, devido a aparente ausência de conectividade lateral e consequente baixa transmissividade.

A limitação no reconhecimento lateral de sistemas estruturais a partir de seções $2 \mathrm{D}$ foi superada pela interpolação e elaboração de mapas de resistividade elétrica para diversas profundidades, a partir de modelos pseudo 3D. A conectividade tridimensional do sistema é claramente expressa abaixo dos $40 \mathrm{~m}$ de profundidade, onde ocorrem três lineamentos de baixa resistividade (em torno de $500 \Omega . \mathrm{m}$ ) em contraste com valores dominantes (acima de $15000 \Omega . m$ ), relacionados respectivamente a fraturas saturadas e ao granito maciço inalterado, cujo cruzamento define um sistema de junta estrutural. 
No estudo a junção de fraturas verticais a partir de $40 \mathrm{~m}$ de profundidade configura o local de maior favorabilidade a perfuração de poço, principalmente diante da possibilidade de recarga por três sistemas de fluxo em fraturas distintas, a partir de um único ponto de captação.

Line 1
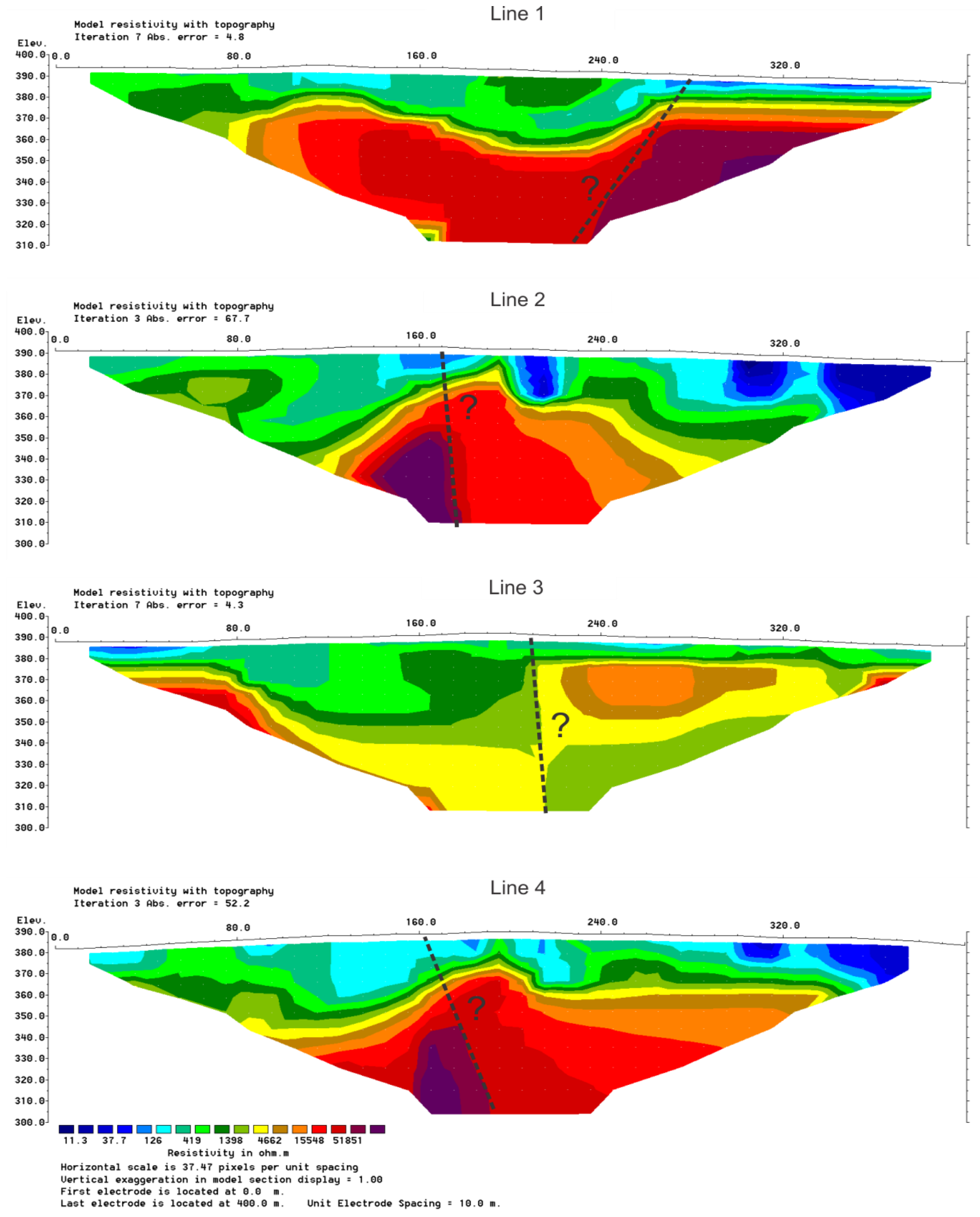

Figura 4 - Modelos de inversão de resistividade elétrica, com topografia e realce de estruturas verticalizadas possivelmente relacionadas a fraturas no maciço rochoso. Fonte: 

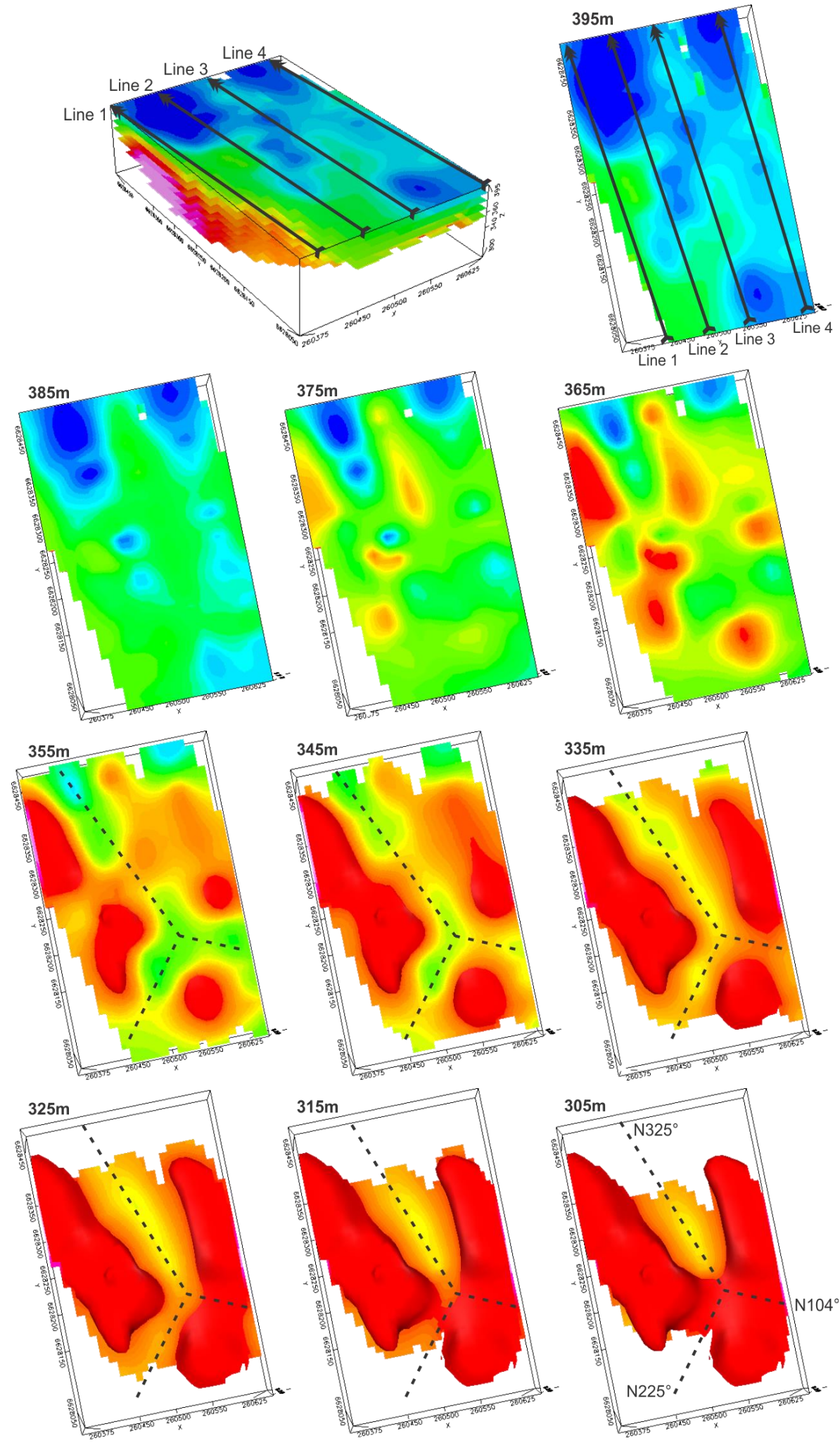

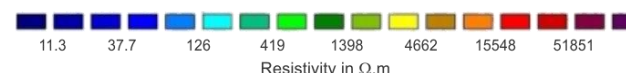

Figura 5 - Modelo pseudo 3D linhas de tomografia elétrica e mapas de resistividade elétrica para diversas profundidades (em metros), com realce de estruturas lineares. 


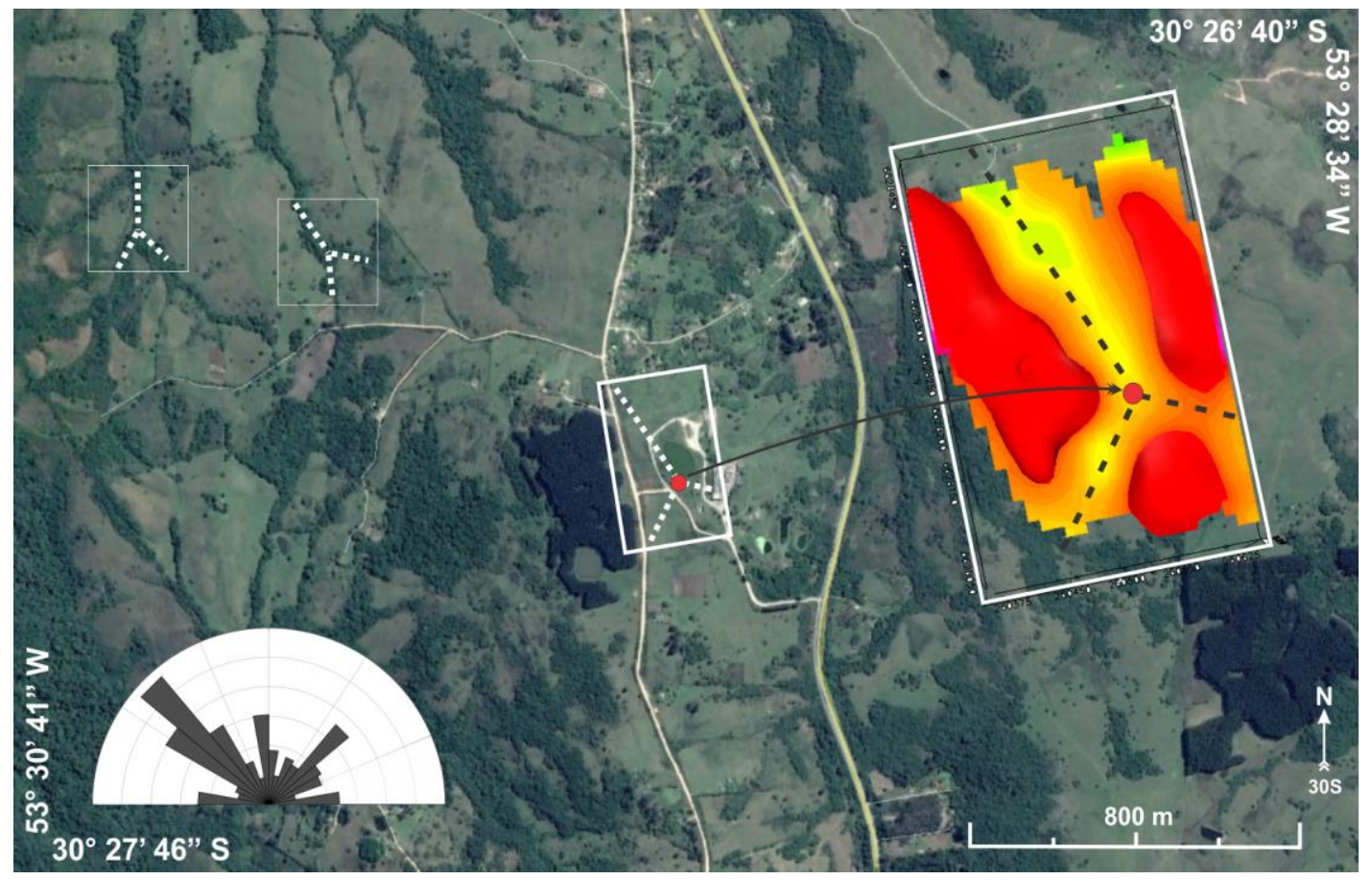

Figura 6 - Orientação de rede de drenagem em sistema estrutural análogo ao reconhecido em modelamento geofísico para o interior do maciço granítico, com destaque de ponto de maior favorabilidade a perfuração de poço (em vermelho).

\section{Agradecimentos}

Agradeço aos docentes e discentes do curso de Geologia da Unesp Rio Claro por todo o suporte oferecido, e as demais pessoas que ofereceram todo o tipo de suporte necessário para realização deste estudo em questão.

\section{Referências}

Brassington, R. 2007. Field Hydrogeology. Chichester, Jonh Wiley \& Sons, 279p.

Hiscock. K.M. 2005. Hydrogeology: principles and practice. Oxford, Blackwell Publishin,405p.

Lee, CH. \& Farmer, I. 1993. Fluid Flow in Discontinuous Rocks. Chapman and Hall, London, 169 p.

Moreira, C.A., Helene, L.P.I., Nogara, P., Ilha, L.M., 2018, Analysis of leaks from geomembrane in a sanitary landfill through models of electrical resistivity tomography in South Brazil. Environmental Earth Sciences, 77(7), https://doi.org/10.1007/s12665-017-7180-x.

Nardy, L.V.S. \& Bitencourt, M.F. 1989. Geologia, petrologia e geoquímica do Complexo Granítico Caçapava do Sul, RS. Revista Brasileira de Geociências, 19(2): 153-169.

Ochoa-González, G.H., Carreón-Freyre, D., Cerca, M., López-Martínez, M., 2015. Assessment of groundwater flow in volcanic faulted areas. A study case in Queretaro, Mexico. Geofísica Internacional, 54(3): 199-220.
Van Golf-Racht, T.D. 1982. Fundamentals of Fractured Reservoir Engineering. Amsterdam, Elsevier, 710 p.

Singhal, B.B.S. \& Gupta, R.P. 2010. Applied hydrogeology of fractured rocks. Berlin, Springer, 429p.

Skinner, D. \& Graham H. 2004. A comparison of electrical and electromagnetic methods for the detection of hydraulic pathways in a fractured rock aquifer, Clare Valley, South Australia. Hydrogeology Journal, 12:576 590.

Tassy, A.; Maxwell, M.; Borgomano, J.; Arfib, B.; Fournier, F.; Gilli, E.; Guglielmi, Y. 2014. Electrical resistivity tomography (ERT) of a coastal carbonate aquifer (Port-Miou, SE France). Environ Earth Sci, 71:601-608.

Zouhri, L. \& Lutz, P. 2016. Hydrogeophysical characterization of the porous and fractured media (chalk aquifer in the Beauvais, France). Environ Earth Sci, 75:343 